\title{
$\mathrm{NIH}$ proceeds with overhaul of grant system
}

A report released at the beginning of September by the National Institutes of Health (NIH) describing a major restructuring of its grant review process has generated highly publicized criticism from some researchers, but other scientists support the changes and contend that the protests are misguided.

The controversy centers on recommendations made in a draft report by the Center for Scientific Review (CSR), the NIH body that reviews $70 \%$ of the grant applications sent to the agency. The CSR, spurred by researchers' concerns that the current grant review system is unfairly biased against new interdisciplinary projects and innovative approaches, began overhauling the system in 1997 (Nature 387, 642; 1997), but the draft report is the first official description of the changes being considered.

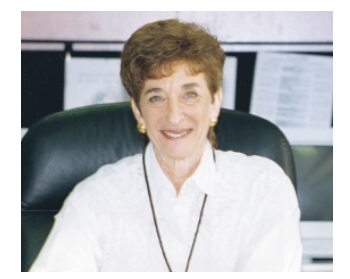

Elvera Ehrenfeld take, say many AIDS researchers.

Elvera Ehrenfeld, director of the CSR, insists that grants will still be reviewed by qualified study sections, and that the current report only describes the reorganization of the IRGs: "Some of the criticism comes from scientists who are expressing concern regarding the absence of details about specific study sections that have been deliberately deferred to Phase 2. These concerns will be addressed at that time, as was stated in the Phase 1 draft report."

The CSR will release a final report establishing the new grant review process early next year. Phase 2 of the overhaul will then begin with an evaluation of the study sections, a process expected to take at least two years.

"Although we're being told that the review groups won't be disassembled, my concern is that once we get

The CSR reviewed around $\$ 9.4$ billion worth of extramural grants in 1999. Under the current system, these grants are sent to study sections composed of volunteer peer reviewers from particular areas of research. In turn, these study sections are grouped into 20 Integrated Review Groups (IRGs) that encompass specific disease categories or research techniques. For example, the "AIDS and AIDS-related research" IRG category includes seven study sections covering one disease.

In Phase 1 of its overhaul of the 50year-old system, CSR has proposed a new list of IRGs, grouping study sections by general scientific discipline rather than by specific disease. So under the new scheme, the AIDS study sections for example, would be distributed between groups such as 'immunology' and 'infectious diseases and microbiology'.

The changes, although seemingly logical, have encountered vocal opposition from AIDS researchers in particular. Mario Stevenson, an HIV virologist at the University of Massachusetts, says, "the [current review] system works well, but isn't perfect," and adds, "from what I've seen of the proposed changes, they're not a step for improvement but potential harm." Because AIDS research often relies on techniques from several different fields, separating virology from immunology study sections would be a mis- to Phase 2 ... what we'll start to see is AIDS grants being reviewed by general virologists," Stevenson warns. "Sometimes I get the feeling that the motives behind the CFR are to defuse the concept that AIDS is a special case," he adds. Other AIDS researchers concur, speculating that NIH may be trying to dissolve the AIDSspecific category as a way of dodging criticism from activists lobbying to establish special categories for other diseases.

Outside the AIDS field, though, the changes have been warmly, if cautiously, received. Vincent Racaniello, a professor of microbiology at Columbia University and editor of the Journal of Virology, believes that the new criteria defined in the draft report will encourage study sections to favor more innovative research. He dismisses the idea that AIDS studies will be harmed. "Apparently the HIV people think they are going to lose their seven study sections," says Racaniello, "but that clearly won't happen, since they exist by political, not scientific mandate." Congress determines the funding levels of the different NIH institutes, which then set the funding priorities that determine the number of study sections for a particular field.

According to Ehrenfeld, Racaniello's response is more typical of the researchers who have offered feedback on the report: "There has been criticism from a few research communities...but the great majority of respondents endorse the activity."

Some respondents have offered more constructive criticism on specific aspects of the report. Sebastian Doniach, former director of the Stanford Synchrotron Radiation Laboratory at the Stanford Linear Accelerator Center, advocates broadening study sections by soliciting mail-in reviews from a larger number of researchers. "This will help alleviate the problems which arise when a given section does not have sufficiently objective expertise to adequately assess a proposal, or where the 'resident experts' tend to represent a built-in cartel," says Doniach.

Alan Dove, New York

\section{Varmus bows out}

The director of the National Institutes of Health (NIH) Harold Varmus, has confirmed that he will leave his post at the end of the year and become President and Chief Executive Officer of Memorial Sloan-Kettering Cancer Center in New York City. The post of NIH director is a political appointment and in a letter to President Clinton, Varmus urged him to

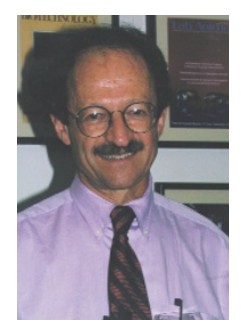

Harold Varmus munity is that Varmus set an exceptionally high standard as director and will be a hard act to follow. He is credited with almost single-handedly persuading Congress to invest so heavily in biomedical research. Under Varmus' leadership, the NIH budget grew to $\$ 15$ billion in FY99 from less than $\$ 11$ billion. The budget could rise by a further \$2 billion in FYOO depending on the outcome of current Labor-HHS appropriahire another medical research scientist to head the agency before Clinton finishes his second term at the end of 2000.

The consensus in the biomedical comtions discussions between the House and the Senate in the US Congress. (see http:// medicine.nature.com/breaking_news)

KAREN BIRMINGHAM, LONDON 